\title{
TUTORIAL PENDIDIKAN AGAMA ISLAM \\ DI UNIVERSITAS NEGERI YOGYKARTA
}

\author{
Syukri Fathudin Achmad Widodo \\ ( Fakultas Teknik- MKU UNY )
}

\begin{abstract}
Abstrak
Tutorial Pendidikan Agama Islam (PAI) merupakan kegiatan kokurikuler yang menekankan pada pendalaman dan penguasaan keterampilan praktek ibadah dan baca tulis Al-Qur'an yang diwajibkan kepada mahasiswa yang mengambil mata kuliah Pendidikan Agama Islam.Artinya kegiatan tutorial PAI melekat pada mata kuliah ini.

Sedangkan pelaksanaannya dilakukan oleh para tutor PAI. Tutor PAI adalah mahasiswa yang telah memenuhi syarat khusus melalui seleksi, pelatihan dan mendapatkan mandat dari dosen PAI. Pada perkembangan selanjutnya tutorial PAI merupakan sarana menyebarkan nilai-nilai Islam yang bertujuan untuk memberikan pendalaman dan penguasaan tambahan keislaman bagi mahasiswa di luar materi perkuliahan pendidikan Agama Islam. Dengan tutorial PAI diharapkan terbentuk sosok pribadi muslim yang utuh, tangguh, menjadi suri tauladan dan sanggup menyebarkan Dakwah Islam (Agent of Change and Inovation) kepada warga kampus maupun masyarakat umum.
\end{abstract}




\section{Pendahuluan}

Dalam undang - undang Sisdiknas Nomor 20 tahun 2003, pasal 3 dinyatakan bahwa : Pendidikan nasional berfungsi mengembangkan kemampuan dan membentuk watak serta peradaban bangsa yang bermartabat dalam rangka mencerdaskan kehidupan bangsa, dan bertujuan berkembangnya potensi peserta didik agar menjadi manusia yang beriman dan bertakwa pada Tuhan Yang Maha Esa, berakhlak mulia, sehat, berilmu, cakap, kreatif, mandiri, dan menjadi warga negara yang demokratis serta bertanggung jawab.

Pendidikan Agama Islam (PAI) yang termasuk komponen Mata kuliah Pengembangan Kepribadian ( MPK) dalam struktur Mata Kuliah umum (MKU) UNY, setidaknya memiliki peran strategis untuk ikut serta memberikan kontribusi bagi pengembangan perilaku, akhlak peserta didik yang memiliki sifat kecendekiawaan, kemandirian dan memiliki kebernuranian.

Pembentukan kepribadian seorang mahasiswa ditempuh melalui proses yang panjang terkait dengan ranah afektif, berbeda dengan proses dengan rumpun mata kuliah yang bersifat kognitif atau psikomotor.Pembentukan kepribadian seseorang tidak hanya melalui pengalaman belajar dikelas saja, tetapi juga dilakukan diluar kelas, misalnya praktek ibadah di Masjid Mujahidin UNY, tadabur alam halaman rektorat, Tutorial PAI .

Menurut Herminarto Sofyan (2008), kecerdasan intelektual, kecerdasan emosional dan kecerdasan spiritual dapat tumbuh dan berkembang secara simultan melalui kegiatan kurikuler dan extrakulrikuler, sehingga dihasilkan insan-insan yang cerdas, santun, berkepribadian, dan menjunjung tinggi nilai-nilai spriritualitas. Ada limawilayah kecerdasan pribadi dalam bentuk kecerdasan emosional yang dapat dibentuk dalam diri mahasiswa. Lima wilayah tersebut adalah :

a. kemampuan mengenali emosi diri, yaitu kemampuan mahasiswa dalam mengenali perasaannya sendiri sewaktu perasaan atau emosi tersebut muncul

b. kemampuan mengelola emosi adalah kemampuan mahasiswa untuk mengendalikan perasaannya sendiri, sehingga tidak meledak dan akhirnya dapat mempengaruhi perilakunya yang salah 
c. kemampuan memotivasi diri sendiri adalah kemampuan memberikan semangat pada diri sendiri untuk melakukan sesuatu yang baik dan bermanfaat

d. kemampuan mengenali emosi orang lain, adalah kemampuan untuk mengerti perasaan dan kebutuhan orang lain, sehingga orang lain mersa senang merasa senang dan mengerti perasaannya, kemampuan ini sering dinamakan Empati.

e. Kemampuan membina hubungan adalah kemampuan untuk mengelola emosi orang lain, sehingga tercipta ketrampilan sosial yang tinggi dan membuat pergaulan mahasiswa menjadi lebih luas

Visi Universitas Negeri Yogyakarta (UNY) sampai tahun 2010 adalah mampu menghasilkan insan cendekia, mandiri dan bernurani. Dalam mewujudkan visi tersebut dibutuhkan kerjasama, tolong-menolong dan persaudaraan. Menurut Sarbiran (2008: 1) supaya visi UNY tersebut dapat mudah diimplementasikan seluruh elemen UNY, dibutuhkan KKT ( Kemauan, Kepedulian dan Tangggung jawab) agar selalu berhasil dan atau semakin baik .

Pun demikian masing-masing pimpinan UNY diharapkan berfungsi sebagai motivator bagi lingkungannya, tak terkecuali dosen mata kuliah pendidikan agama Islam ( PAI) beserta para tutor PAI. Meskipun mata kuliah ini hanya 3 SKS dan ratarata ditempuh mahasiswa pada awal semester, diharapkan memiliki andil dalam pembentukan karakter mahasiswa. Namun harus diakui beban materi yang ajarkan sesuai rambu-rambu Dikti Depdiknas yang sarat bermuatan ranah kognisi, mengharuskan para dosen untuk mengembangkan dan berkreasi sesuai dengan silabus PAI UNY yang tentunya berdasarkan Visi dan Misi UNY tersebut.

Pendidikan Agama Islam di Perguruan Tinggi Umum (PTU) seperti halnya di Universitas Negeri Yogyakarta (UNY) berguna untuk membantu terbinanya mahasiswa yang beriman dan bertaqwa kepada Allah SWT, berbudi pekerti luhur, berpikir filosofis, bersikap rasional dan dinamis, berpandangan luas ikut serta mewujudkan Indonesia yang utuh aman, sejahtera yang diridhoi Allah SWT. Apabila dilihat dari nilai gunanya, nampaknya sungguh sangat indah dan idealis, tetapi jika dilihat dari proses pelaksanaannya, menimbulkan pertanyaan besar?, Mungkinkah merubah kepribadian, watak dan akhlak seseorang hanya dalam waktu satu semester ? Wallahu'alam bis shoab. 
Sedangkan visi dan misi mata kuliah PAI sebagai berikut

Visi : Menjadikan ajaran Islam sebagai sumber nilai, dan pedoman yang mengantarkan mahasiswa dalam mengembangkan profesi dan kepribadian Islami

Misi :

Terbinanya mahasiswa yang beriman, bertaqwa, berilmu, dan berakhlak mulia, serta menjadikan ajaran Islam sebagai landasan berpikir dan berperilaku dalam pengembangan profesi.

\section{Tutorial Pendidikan Agama Islam (PAI)}

Tutorial PAI merupakan kegiatan kokurikuler yang menekankan pada pendalaman dan penguasaan keterampilan praktek ibadah dan baca tulis Al-Qur'an yang diwajibkan kepada mahasiswa yang mengambil mata kuliah Pendidikan Agama Islam.

Kegiatan tutorial PAI ini relevan dengan model belajar cooperative learning, karena itu proses pembelajarannya diselenggarakan dalam kegiatan belajar mengajar tutorial (kbmt) diluar jam perkuliahan pendidikan agama Islam, sedangkan tutor berasal dari teman sebaya, artinya dilakukan dengan prinsip belajar bersama(Syukri,2006:16).

Pada perkembangan selanjutnya tutorial PAI merupakan sarana menyebarkan nilai-nilai Islam yang bertujuan untuk memberikan pendalaman dan penguasaan tambahan keislaman bagi mahasiswa di luar materi perkuliahan pendidikan Agama Islam. Dengan tutorial PAI diharapkan terbentuk sosok pribadi muslim yang utuh, tangguh, menjadi suri tauladan dan sanggup menyebarkan Dakwah Islam (Agent of Change and Inovation) kepada warga kampus maupun masyarakat umum.

\section{Visi Tutorial PAI :}

"Mewujudkan Masyarakat Kampus yang Bernurani,Cendekia, dan Mandiri, melalui Pengelolaan Tutorial yang Profesional"

\section{Misi Tutorial PAI :}

1. Membentuk pribadi muslim yang memiliki kecerdasan spiritual, emosional dan intelektual

2. Meningkatkan profesionalisme dalam pengelolaan tutorial

3. Membentuk lingkungan kegiatan tutorial yang kondusif bagi peserta tutorial

4. Meningkatkan kualitas dan kuantitas sumber daya tutor 
5. Mewujudakan mahasiswa yang berprestasi dan mampu mengaktualisasikan nilai-nilai Islam

\section{Kedudukan dan status Tutorial Pendidikan Agama Islam :}

a. Sifatnya wajib diikuti oleh seluruh mahasiswa UNY yang mengambil mata kuliah Pendidikan Agama Islam.

b. Merupakan pendukung mata kuliah PAI yang dimaksudkan untuk pendalaman atau perluasan materi PAI dan aspek ibadah

c. Mahasiswa yang telah mengikuti tutorial PAI dengan ketentuan pertemuan kegiatan belajar mengajar tutorial (kbmt) dan mengikuti kuliah akhir semester atau pesantren sehari akan mendapatkan nilai akhir tutorial.

d. Kedudukan nilai akhir tutorial PAI adalah sebagai nilai yang ikut dipertimbangkan dalam penentuan nilai akhir mata kuliah PAI oleh dosen pengampu PAI atau berkontribusi setara dengan $15 \%$ dari total.

\section{Adapun Kegiatan tutorial PAI meliputi :}

\section{a. ORIENTASI}

Orientasi merupakan kegiatan awal, memberikan informasi tentang sillabus, materi dan kontrak belajar antara tutor dan peserta

\section{b. KBMT}

Merupakan Kegiatan Belajar Mengajar Tutorial yang dilaksanaan selama 1 semester yang meliputi KBMT Klasikal pada awal pertemuan, yang dilanjutkan dengan KBMT Kelompok yang didamping oleh seorang Tutor minimal selama 9 kali pertemuan.Di pertengahan kegiatan ini terdapat seminar yang merupakan kegiatan suplemen yang diberikan kepada peserta.Dalam kegiatan tutorial ini terdapat Ujian Akhir Semester dengan materi yang disampaikan dalam kegiatan KBMT Kelompok.

\section{c. PESANTREN SEHARI}

Merupakan kegiatan penutupan Pelaksanaan Kegiatan Belajar Mengajar Tutorial yang dilaksanakan pada akhir semester. Diharapkan pada kegiatan Pesantren sehari, dapat dilanjutkan dengan Tutorial Lanjut. 


\section{d. KAJIAN KELAS}

Merupakan kajian keislaman di masing-masing kelas untuk menambah wawasan keislaman yang dilakukan minimal sekali dalam satu bulan

\section{Materi Tutorial PAI}

Materi yang diberikan dalam Tutorial lebih banyak bertujuan kepada aplikasi :

1. Ibadah (Thaharah, Sholat)

2. Bacaan Al Qur'an.

3. Akhlaq.

Materi Tutorial disesuaikan dengan tujuan dasar pelaksanaan Tutorial. Bagaimana mahasiswa baru muslim bisa lurus aqidah, baik ibadahnya lancar bacaan Al Qur'annya serta mulia akhlaq dan kepribadiannya.

Manajemen tutorial dalam rangka meningkatkan Kuantitas dan Kualitas Sumberdaya manusia

\section{a. Rekruitmen Tutor melalui Bina Tutor (Bintor)}

\section{Target dan Tujuan:}

- Dilakukan 2 kali dalam 1 tahun

- Diharapkan menambah jumlah tutor

- Target Ideal tiap tahun adalah 400 tutor aktif dengan perbandingan ideal 1 tutor : 10 peserta

\section{Alur perekrutan tutor :}

KBMT---Tutorial Lanjut (Up grade dan persiapan calon tutor) - Pendaftaran --- Tes ( wawancara, tertulis, ibadah, BAQ, microteaching)—(lulus, lulus bersyarat, tidak lulus)—Tutor Muda

\section{b. UP GRADE TUTOR}

Yaitu kegiatan untuk memberikan pencerahan dan penyegaran baik untuk tutor muda maupun tutor senior

\section{Tutor Muda}

- Short Course (suplemen awal tutor yan lulus dalam seleksi calon tutor)

- Suplemen periodik tutor muda ( minimal 4 kali pertemuan)

Tutor senior

Madrasah Tutor dilaksanakan tiap 2 pekan sekali 


\section{d. Koordinasi Dosen dan Tutor PAI}

Kegiatan ini berisi koordinasi dan konsolidasi antara dosen dan tutor PAI, yang dilaksanakan tiap semester sekali. Dengan mendatangkan narasumber yang relevan diharapkan kegiatan ini dapat meng-up date keilmuan sekaligus meningkatkan kompetensi profesional dan kompetensi pedagogik dosen dan tutor PAI.

Berikut ini beberapa narasumber yang pernah mengisi kegiatan koordinasi dosen dan tutor PAI di UNY

\begin{tabular}{|c|c|c|c|c|}
\hline No. & Nama & Institusi & Tema & Ket \\
\hline 1. & Dr. Rahmat Wahab & UNY & $\begin{array}{l}\text { Pembelajaran orang } \\
\text { dewasa }\end{array}$ & $\begin{array}{l}\text { Semester } \\
\text { Genap } \\
2006 / 07\end{array}$ \\
\hline 2. & Dr. Khoirudin Bashori & UMY & $\begin{array}{l}\text { Membangun Jatidiri } \\
\text { Muslim yang Tangguh }\end{array}$ & $\begin{array}{l}\text { Smt } \\
\text { Gasal } \\
2007 / 08\end{array}$ \\
\hline 3. & Prof. Sarbiran, Ph.D & UNY & $\begin{array}{l}\text { Pengembangan Softskill } \\
\text { mahasiswa }\end{array}$ & $\begin{array}{l}\text { Smt } \\
\text { Genap } \\
07 / 08\end{array}$ \\
\hline 4. & Dr. Marzuki, M.Ag & UNY & Pengembangan materi PAI & $\begin{array}{l}\text { Smt } \\
\text { Genap } \\
07 / 08\end{array}$ \\
\hline 5. & Sumarno, Ph.D & UNY & $\begin{array}{l}\text { Model Pembelajaran PAI } \\
\text { dengan } \quad \text { Contextual } \\
\text { Teaching \& Learning }\end{array}$ & $\begin{array}{l}\text { Smt } \\
\text { Gasal } \\
08 / 09\end{array}$ \\
\hline 6. & Mami Hajaroh, M.Pd & UNY & $\begin{array}{lr}\text { Sistem } & \text { Evaluasi } \\
\text { Pembelajaran } & \text { Tutorial PAI }\end{array}$ & $\begin{array}{l}\text { Smt } \\
\text { Genap } \\
08 / 09\end{array}$ \\
\hline 7. & Drs.Suparlan & UNY & $\begin{array}{l}\text { Otokritik pelaksanaan } \\
\text { Tutorial PAI UNY }\end{array}$ & $\begin{array}{l}\text { Smt } \\
\text { Genap }\end{array}$ \\
\hline
\end{tabular}




\begin{tabular}{|l|l|l|l|l|}
\hline 8. & Dr. Ajat Sudrajat, M.Ag & UNY & $\begin{array}{l}\text { Pengembangan } \\
\text { Pembelajaran PAI dari 2 } \\
\text { SKS menjadi 3 SKS }\end{array}$ & $\begin{array}{l}\text { Smt } \\
\text { Gasal } \\
09 / 10\end{array}$ \\
\hline 9 & Dr.Siti Irine Astuti & UNY & $\begin{array}{l}\text { Pengenalan Motivasi } \\
\text { Belajar dengan Brain Gym }\end{array}$ & $\begin{array}{l}\text { Smt } \\
\text { Genap } \\
09 / 10\end{array}$ \\
\hline
\end{tabular}

Target Program Kerja Tutorial PAI UNY ( Ardiansyah,2007)

- $\quad$ Target jangka pendek.

1. Tercapainya akhlaq yang baik kepada Mahasiswa baru.

2. Memahami hakekat dan kewajiban shalat lima waktu. Ada perubahan yang lebih baik dalam melaksanakan shalat.

3. Mahasiswa baru muslim yang belum bisa baca Al Qur'an bisa mengetahui baca Al Qur'an dalam program P2BAQ.

4. Melakukan perlindungan kepada Mahasiswa baru ( MABA) terhadap aliran sesat di UNY.

5. Pendataan Mahasiswa yang terlibat dalam penyebaran aliran sesat di kampus .

6. Profesional dalam pelaksanaan Kegiatan Belajar Mengajar Tutorial (KBMT)

7. Komunikasi efektif dengan dosen PAI, jajaran Pembantu Rektor 1 , Para Pembantu Dekan I

\section{Penutup}

Tutorial PAI merupakan bagian dari matakuliah Pendidikan Agama Islam. Karenanya tugas para tutor menyampaikan pembelajaran dengan penuh keikhlasan dan tanggung jawab sesuai dengan visi dan misinya. Dosen PAI wajib memberikan masukan dan pencerahan agar para tutor tidak melenceng dalam memberikan tutorial PAI. Dan dukungan dana dari Rektorat khususnya Pembantu Rektor 1 begitu penting untuk menjalankan roda kehidupan tutorial PAI di UNY. Semoga Tutorial Pendidikan Agama Islam mampu memberi warna dan pencerahan bagi terciptanya visi UNY. 


\section{DAFTAR PUSTAKA}

Ardiansyah ( 2007 ) Materi Workshop Tutorial PAI UNY

Herminarto Sofyan ( 2008) Pengembangan Soft skill Mahasiswa, Majalah Dinamika UNY, Edisi Dies Natlis UNY Mei 2008 , Humas UNY

Sarbiran ( 2008) Pemikiran praktis Membangun Kultur BCM di UNY, makalah tidak dipublikasikan dalam Semiloka Lemlit UNY, 1 Desember 2008

Sumarno ( 2008 ) Model Pembelajaran Pendidikan Agama Islam berdasarkan Contextual and Teaching ( CTL), Makalah Koordinasi Dosen dan Tutor Pendidikan Agama Islam, 14 Februari 2008

Suparlan ( 2009) Otokritik Pelaksanaan Tutorial PAI di UNY Yogyakarta, makalah Koordinasi Dosen dan Tutor Pendidikan Agama Islam, 9 Februari 2009

Syukri Fathudin AW ( 2006) Menerapkan metode cooperative learning dalam pembelajaran Pendidikan Agama Islam, Jurnal Humanika, UPT MKU UNY Yogyakarta

Syukri Fathudin AW, Sudiyatno (2009) Peningkatan Perilaku Religius Mahasiswa Melalui Integrasi PembelajaranPendidikan Agama Islam (PAI) Dan PembinaanDi Unit Kegiatan Keagamaan Mahasiswa, Jurnal Humanika, UPT MKU UNY Yogyakarta

\section{Biodata Penulis}

Syukri Fathudin Achmad Widodo, dilahirkan di Kab.Semarang pada 12 Maret 1975, menyelesaikan sarjana pada STAIN Salatiga dan pascasarjana pada UNNES Semarang, saat ini berkarya sebagai pengajar pada jurusan Pendidikan Teknik Mesin FT UNY dan unit MKU UNY. 
